\title{
CONDIÇÕES SOCIAIS, ESCOLARIZAÇÃO E HÁBITOS DE ESTUDO NO DESEMPENHO ACADÊMICO DE CONCLUINTES DA ÁREA DA SAÚDE
}

\author{
SOCIAL CONDITIONS, SCHOOLING AND STUDY HABITS IN THE ACADEMIC \\ PERFORMANCE OF FINALISTS IN THE FIELD OF HEALTH
}

\author{
Luiz Roberto Augusto Noro iD (00000-0001-8244-0154) ${ }^{1}$, José Luis Medina Moya (DD)(0000-0002-9487-9065) ${ }^{2}$ \\ ${ }^{1}$ Universidade Federal do Rio Grande do Norte, Centro de Ciências da Saúde, Natal, Rio Grande do \\ Norte, Brasil.<luiznoro@ccs.ufrn.br> \\ ${ }^{2}$ Universidade de Barcelona, Faculdade de Educação, Departamento de Ensino e Organização \\ Educacional, Barcelona, Espanha.
}

Resumo Vários fatores contribuem para a dificuldade no acesso e permanência na Educação Superior no Brasil. O objetivo deste estudo foi identificar a diferença de desempenho dos estudantes por condições socioeconômicas, escolarização e hábitos de estudo. Foi realizado estudo transversal analítico com base nos dados do Exame Nacional de Desempenho dos Estudantes, em amostra de 196.856 alunos dos cursos de saúde em 2013. A nítida barreira que estudantes de classes sociais menos favorecidas apresentam para ingresso e permanência na Educação Superior requer uma permanente busca de maior justiça social. Enquanto se mantiver a atual situação, é papel do governo proporcionar estratégias que viabilizem o acesso à Educação Superior por meio de políticas afirmativas e recursos para viabilizar que pessoas com piores condições socioeconômicas possam investir em sua formação. A bolsa-permanência apresentou-se como essencial na busca da equidade, assim como a bolsa acadêmica permitiu melhor desempenho, em especial, pelo maior vínculo com a Instituição de Educação Superior.

Palavras-chave educação superior; condições socioeconômicas; escolarização; hábitos de estudo; equidade.
Abstract Many factors contribute to the difficulty in accessing and remaining in Higher Education in Brazil. The objective of the present study was to identify the difference in the performance of the students due to socioeconomic conditions, schooling and study habits. We conducted an analytical cross-sectional study based on the data of the National Student Performance Exam (Exame Nacional de Desempenho dos Estudantes, in Portuguese), with a sample of 196,856 students from health courses in 2013. The clear obstacle faced by the students from underprivileged social classes to their admission and permanence in Higher Education requires a constant struggle for greater social justice. While the current situation remains unchanged, it is the role of the government to provide strategies to make viable the access to Higher Education through affirmative policies and resources to make it possible for the underprivileged to invest in their education. The permanence scholarship presented itself as crucial in the struggle for equity, and it enabled a better performance on the part of the students, especially due to their stronger ties with the Higher Education Institution.

Keywords higher education; socioeconomic conditions; schooling; study habits; equity. 


\section{Introdução}

A dificuldade na equidade ao acesso à Educação Superior no Brasil tem como fatores determinantes, entre outros, a desigualdade social, marcada pela concentração de renda e as condições da formação proporcionada em grande parte das escolas.

Na área da Saúde, essa perspectiva ganha contornos ainda mais interessantes, pois a possibilidade de fazer o bem continua sendo um dos grandes princípios éticos do ser humano e do aluno que opta por essa área de conhecimento. Outro elemento importante da área da saúde é a perspectiva favorável de ingresso no mercado de trabalho, uma vez que essas profissões se configuram como essenciais na qualidade de vida das pessoas. Esses fatores fazem com que os cursos dessa área apresentem alta concorrência nos processos seletivos, aumentando a dificuldade para ingresso. Natural que, sem medidas que diferenciem os candidatos segundo sua inserção social e, por conseguinte, seu processo formativo, o acesso à Educação Superior nessa área, com destaque para os cursos de Medicina, torna-se quase inviável.

Essa situação desperta, nas classes sociais menos favorecidas, um distanciamento da possibilidade do acesso à Educação Superior passível de direcioná-la à mobilidade social, constituindo-se como um desejo de superar a condição da própria família por meio da formação superior (Brocco, 2017).

Os debates sobre essa questão apresentam posições que questionam iniciativas de inclusão por meio de ações afirmativas (Maio e Santos, 2007), bem como as que defendem estas intervenções como forma de atenuar as discrepâncias presentes na sociedade (Haas e Linhares, 2012). Há também aqueles que as questionam por entendê-las como mero mecanismo de consentimento de espaço limitado, contrapondo-se à efetiva inclusão universal e com base na justiça social (Fonseca, 2014; Lima, 2014). De todas essas posições, o mérito acadêmico individual do aluno, isoladamente, não deve ser o principal referencial para a disputa observada no acesso à Educação Superior. Isso porque tal instrumento somente é válido quando se trata de sujeitos com iguais oportunidades de formação pregressa, o que não é o caso da composição da sociedade brasileira (Santos e Scopinho, 2016).

Em estudo realizado em escolas públicas na região metropolitana de São Paulo (Souza e Vazquez, 2015) observou-se o interesse de jovens provenientes dessas instituições em ingressar na Educação Superior. As variáveis autodefinição de raça e de classe social, escolaridade, tipo de ocupação dos pais ou responsáveis e experiência atual e anterior de trabalho são determinantes para o aumento ou diminuição nessas expectativas.

Existe produção científica que sinaliza forte correlação entre resultados escolares e o nível socioeconômico e cultural das famílias (Alves, Soares e Xavier, 2014). Do mesmo modo, há estudos os quais assinalam evidências que comprovam a importância das origens sociais no processo de construção 
do sucesso escolar de crianças e jovens (Rodrigues et al., 2011). Entretanto, pesquisas também indicam uma correlação entre desempenho acadêmico e as características pessoais dos estudantes e das escolas frequentadas (Formiga, 2004).

Um dos argumentos daqueles que defendem a não disponibilidade de acesso à Educação Superior por meio de políticas afirmativas baseia seu ponto de vista no possível baixo desempenho acadêmico desses alunos, considerando sua história escolar pregressa (Haas e Linhares, 2012). Considerando que o universo acadêmico na atualidade trabalha concretamente com essa situação, é necessário identificar o quanto esses argumentos são efetivos e como eles interferem na formação dos profissionais da área da Saúde.

Para identificar o potencial das condições socioeconômicas, do percurso da escolarização dos estudantes e de seus familiares, dos hábitos de estudo ao longo do curso de graduação, essas variáveis foram avaliadas a partir do desempenho dos concluintes no Exame Nacional de Desempenho dos Estudantes (Enade) do ano de 2013. No presente estudo, os cursos de bacharelado participantes foram: Biomedicina, Educação Física, Enfermagem, Farmácia, Fisioterapia, Fonoaudiologia, Medicina, Medicina Veterinária, Nutrição, Odontologia, Serviço Social e Terapia Ocupacional.

O Enade avalia o desempenho dos alunos concluintes dos cursos de graduação, configurando-se como um dos instrumentos que compõe o Sistema Nacional de Avaliação da Educação Superior (Sinaes). Tal exame é constituído por 40 questões das quais dez referem-se à formação geral (comportamento ético, compromisso social, espírito científico, humanístico e reflexivo, capacidade de análise crítica e integrada à realidade e à capacidade de socializar o conhecimento em vários contextos). As outras 30 são relativas à formação específica, baseada nas competências e habilidades previstas nas Diretrizes Curriculares Nacionais (DCN) dos cursos de graduação. Por sua característica de dispositivo avaliativo amplo e multivariado (Fernández, 2011), o Enade é considerado potente na perspectiva de garantir as características básicas de validade, flexibilidade, confiabilidade e imparcialidade, essenciais em um processo avaliativo. Para Noro et al. (2016), é papel preponderante do Enade estimular, com base em seus resultados, a autoavaliação dos cursos, proporcionando real empoderamento dos professores, dos alunos e de toda a comunidade acadêmica, na perspectiva de contribuição concreta na consolidação das Diretrizes Curriculares Nacionais dos cursos de graduação da área da Saúde.

Considerando essas premissas, foi objetivo do presente estudo identificar a diferença de desempenho dos estudantes concluintes de IESs da área da Saúde, considerando suas condições socioeconômicas, o percurso da escolarização dos pais e os hábitos de estudo por meio dos resultados do Enade de 2013. 


\section{Percurso metodológico: o desafio permanente de acessar dados potencial- mente públicos}

Trata-se de estudo individuado, uma vez que a unidade de observação e de análise foi cada um dos alunos participantes do Enade, de corte transversal analítico, realizado com base nos dados secundários do Enade 2013. A amostra do estudo foi composta pelos concluintes de todos os cursos da área da saúde no ano de 2013 que se submeteram ao referido exame.

Para solicitar os microdados, foi contatado o Instituto Nacional de Estudos e Pesquisas Estatísticas (Inep), órgão do Ministério da Educação encarregado da autorização de funcionamento e regulação dos cursos de Educação Superior e fiel depositário dos dados da prova que compõem o Enade.

Após apresentação do projeto de pesquisa à Diretoria de Avaliação do Ensino Superior (DAES) do Inep e do encaminhamento do termo de confidencialidade e sigilo por parte do pesquisador responsável pela pesquisa, foi deferida a carta de anuência da DAES, a qual embasou a submissão do projeto ao Comitê de Ética em Pesquisa do Hospital Onofre Lopes Pesquisa (CEP-HUOL) por meio da Plataforma Brasil (CAAE 55838816.7.000.5292), conforme princípios estabelecidos pela Resolução 466/2012 do Conselho Nacional de Saúde.

Para acesso aos microdados, foi solicitada autorização ao Serviço de Atendimento ao Pesquisador do Inep, por meio de ofício e apresentação do parecer 1.557.954 de 24 de maio de 2016, aprovado pelo CEP-HUOL, atendendo aos preceitos da Portaria Inep n. 467, de 19 de setembro de 2014.

Uma vez autorizado pela Diretoria de Estudos Educacionais, foram agendados quatro dias em ambiente seguro nas instalações do Inep, no qual apenas um dos pesquisadores foi autorizado a ter acesso. Para a construção do banco de dados e consolidação dos resultados, o pesquisador utilizou os computadores disponibilizados pelo Inep, com programas específicos para a devida análise. Esse procedimento é necessário para a garantia do sigilo das informações e proteção da identidade dos estudantes e das IESs envolvidos na pesquisa. Por este motivo, representa uma pressão ao pesquisador, uma vez que qualquer análise posterior somente seria possível com novo agendamento com o Inep.

Para o desenvolvimento da pesquisa, foram previamente definidos os bancos de dados do Inep que seriam acessados, assim como os programas que seriam utilizados para a análise, uma vez que os dados primários não são passíveis de serem acessados em outro ambiente que não o do referido instituto. 
Após quatro dias de trabalho diuturno em cabines totalmente isoladas, para as quais era necessária uma cuidadosa revista preliminar a cada momento que se entrava e se saía do ambiente, todos os dados coletados ficavam armazenados em arquivos específicos, nomeados pelo pesquisador. Com esta perspectiva, não foi possível acessar os dados primários em outro momento que não durante a coleta de dados no ambiente seguro.

Esses arquivos, resultantes da consolidação dos resultados, foram mantidos no laboratório de informática da sala segura do Inep, os quais somente foram liberados ao pesquisador após serem auditados por profissionais do instituto, garantindo, dessa forma, que as informações fornecidas não permitissem identificação quer dos estudantes participantes do Enade 2013, quer das IESs.

O banco de dados foi composto pelas informações relativas ao desempenho nas questões que compuseram o Enade 2013 (trinta e cinco questões objetivas e cinco questões dissertativas) e às condições socioeconômicas, escolarização individual e da família e hábitos de estudo do aluno concluinte, presentes no questionário previamente preenchido pelos estudantes, quando da inscrição no exame.

A variável dependente do estudo refere-se às diferenças das médias do desempenho global dos estudantes no Enade 2013. As variáveis independentes foram definidas com base na condição sociodemográfica do aluno (estado civil, trabalho, renda familiar, cor da pele, tipo de ensino médio, cotas e bolsapermanência). Outros quesitos foram a escolarização dos pais, os hábitos de estudo (bolsa acadêmica, intercâmbio e horas de estudo por semana) e tipo de IES na qual se formou (universidade ou outras).

O banco de dados foi exportado para o software R, versão 3.1.117. Os dados foram submetidos à análise estatística descritiva e inferencial baseada nas hipóteses de associação e correlação indicadas pelas variáveis por meio do programa SPSS 2.0, disponibilizado pelo Inep. Para as comparações entre as médias no desempenho global e as variáveis relacionadas às diferentes categorias propostas no estudo, foi utilizada a análise de variância (Anova), com nível de significância de $\mathrm{p}<0,001$.

\section{Fatores que podem contribuir com o desempenho na educação superior}

O Enade 2013 avaliou 196.856 alunos concluintes, envolvendo todas as IESs brasileiras, tanto de estabelecimentos públicos como privados, em suas diferentes categorias acadêmicas, ou seja, universidades, centros universitários e faculdades.

A distribuição dos alunos segundo as variáveis propostas pelo estudo está na Tabela 1. 
Tabela 1

\begin{tabular}{|c|c|c|}
\hline Condição & Total & $\%$ \\
\hline \multicolumn{3}{|l|}{ Estado civil } \\
\hline Solteiro & 124126 & 73,8 \\
\hline Não solteiro & 44094 & 26,2 \\
\hline \multicolumn{3}{|l|}{ Cor } \\
\hline Branco ou amarelo & 100515 & 59,8 \\
\hline Negro pardo mulato indígena & 67607 & 40,2 \\
\hline \multicolumn{3}{|l|}{ Renda familiar } \\
\hline$+6 \mathrm{SM}$ & 44080 & 26,2 \\
\hline $0-6 S M$ & 123954 & 73,8 \\
\hline \multicolumn{3}{|l|}{ Trabalho } \\
\hline Não & 87916 & 52,4 \\
\hline Sim & 79937 & 47,6 \\
\hline \multicolumn{3}{|l|}{ Ensino médio } \\
\hline Pública & 104974 & 62,6 \\
\hline Privada & 62820 & 37,4 \\
\hline \multicolumn{3}{|l|}{ Bolsa-permanência } \\
\hline Não & 154595 & 92,0 \\
\hline Sim & 13365 & 8,0 \\
\hline \multicolumn{3}{|l|}{ Cotas } \\
\hline Não & 141616 & 84,4 \\
\hline Sim & 26108 & 15,6 \\
\hline \multicolumn{3}{|l|}{ Escolarização do pai } \\
\hline Ensino médio à pós-graduação & 87890 & 52,4 \\
\hline Até ensino fundamental & 79803 & 47,6 \\
\hline \multicolumn{3}{|l|}{ Escolarização da mãe } \\
\hline Ensino médio à pós-graduação & 100263 & 59,7 \\
\hline Até ensino fundamental & 67685 & 40,3 \\
\hline \multicolumn{3}{|l|}{ Bolsa acadêmica } \\
\hline Sim & 39257 & 23,4 \\
\hline Não & 128729 & 76,6 \\
\hline \multicolumn{3}{|l|}{ Intercâmbio } \\
\hline Sim & 4753 & 2,8 \\
\hline Não & 163209 & 97,2 \\
\hline \multicolumn{3}{|l|}{ Horas de estudo } \\
\hline $8 \mathrm{ou}+$ & 42334 & 25,2 \\
\hline Até 7 horas & 125739 & 74,8 \\
\hline
\end{tabular}

Fonte: Inep, 2016

A maioria da população estudantil é solteira $(73,8 \%)$, cuja cor de pele é branca $(59,8 \%)$, com renda familiar entre 0 e 6 salários mínimos $(73,8 \%)$, cursou ensino médio majoritariamente em escola pública $(62,6 \%)$ e dedicou sete horas ou menos de estudo individual por semana. Os cotistas ocupam apenas $15,6 \%$ das vagas, ou seja, menos do que as $20 \%$ disponibilizadas por lei. Mesmo com essa defasagem, o sistema de cotas oportuniza o acesso a um número significativo de alunos, os quais, sem o sistema de cotas, dificilmente teriam oportunidade de acesso à Educação Superior (Felicetti e Morosini, 2009). São observadas, também, iniciativas de estímulo ao vínculo com as IES, como as bolsas acadêmicas $(23,4 \%)$, as bolsas-permanência $(8 \%)$ e o intercâmbio durante a graduação com instituições no exterior (2,8\%). Essas estratégias visam garantir a equidade não somente no acesso, mas também para que os 
alunos permaneçam na Educação Superior, desenvolvendo-o com qualidade (Felicetti e Morosini, 2009).

Com base nesses resultados, buscou-se compreender que variáveis teriam relação com o melhor desempenho dos alunos no ENADE 2013. O desempenho dos alunos considerando as condições socioeconômicas, escolarização da família e hábitos de estudo encontra-se na Tabela 2.

Tabela 2

Média e diferença do desempenho dos alunos dos cursos da área da Saúde por condições socioeconômicas, escolarização da família e hábitos de estudo, em todas as instituições de ensino superior e universidades, ENADE, 2013.

\begin{tabular}{|c|c|c|c|c|c|c|}
\hline Condição & Todas & $\mathbf{p}$ & Diferença & Universidade & $\mathbf{p}$ & Diferença \\
\hline \multicolumn{7}{|l|}{ Estado civil } \\
\hline Solteiro & 46,19 & $<0,001$ & 4,41 & 47,33 & $<0,001$ & 6,88 \\
\hline Não Solteiro & 41,78 & & & 40,46 & & \\
\hline \multicolumn{7}{|l|}{ Cor } \\
\hline Branca/Amarela & 46,13 & $<0,001$ & 2,73 & 46,96 & $<0,001$ & 3,60 \\
\hline $\begin{array}{l}\text { Negra/Parda/ } \\
\text { Indígena }\end{array}$ & 43,40 & & & 43,36 & & \\
\hline \multicolumn{7}{|l|}{ Renda } \\
\hline$+6 \mathrm{SM}$ & 47,72 & $<0,001$ & 3,64 & 48,81 & $<0,001$ & 4,49 \\
\hline $0-6 S M$ & 44,08 & & & 44,32 & & \\
\hline \multicolumn{7}{|l|}{ Trabalho } \\
\hline Não & 46,97 & $<0,001$ & 4,06 & 48,41 & $<0,001$ & 6,32 \\
\hline Sim & 42,90 & & & 42,10 & & \\
\hline \multicolumn{7}{|l|}{ Ensino médio } \\
\hline Privada & 47,66 & $<0,001$ & 4,18 & 48,86 & $<0,001$ & 5,52 \\
\hline Pública & 43,48 & & & 43,34 & & \\
\hline \multicolumn{7}{|l|}{ Bolsa-permanência } \\
\hline Não & 44,78 & $<0,001$ & $-3,39$ & 45,18 & $<0,001$ & $-4,25$ \\
\hline Sim & 48,17 & & & 49,43 & & \\
\hline \multicolumn{7}{|l|}{ Cotas } \\
\hline Não & 44,87 & $<0,001$ & $-1,25$ & 45,57 & 0,019 & $-0,33$ \\
\hline Sim & 46,12 & & & 45,90 & & \\
\hline \multicolumn{7}{|l|}{ Escolarização do pai } \\
\hline Ensino médio à pós & 46,87 & $<0,001$ & 3,81 & 48,09 & $<0,001$ & 5,39 \\
\hline Ensino fundamental & 43,06 & & & 42,70 & & \\
\hline \multicolumn{7}{|l|}{ Escolarização da mãe } \\
\hline Ensino médio à pós & 46,76 & $<0,001$ & 4,24 & 47,95 & $<0,001$ & 5,98 \\
\hline Ensino fundamental & 42,51 & & & 41,97 & & \\
\hline \multicolumn{7}{|l|}{ Bolsa acadêmica } \\
\hline Sim & 51,10 & $<0,001$ & 7,91 & 52,18 & $<0,001$ & 9,49 \\
\hline Não & 43,19 & & & 42,68 & & \\
\hline
\end{tabular}


Continuação da Tabela 2.

Média e diferença do desempenho dos alunos dos cursos da área da Saúde por condições socioeconômicas, escolarização da família e hábitos de estudo, em todas as instituições de ensino superior e universidades, ENADE, 2013.

\begin{tabular}{|c|c|c|c|c|c|c|}
\hline \multicolumn{7}{|l|}{ Fez intercâmbio } \\
\hline Sim & 49,19 & $<0,001$ & 4,26 & 50,58 & $<0,001$ & 5,15 \\
\hline Não & 44,93 & & & 45,43 & & \\
\hline \multicolumn{7}{|c|}{ Horas estudo/semana } \\
\hline 8 ou + horas & 48,29 & $<0,001$ & 4,34 & 49,25 & $<0,001$ & 4,98 \\
\hline Até 7 horas & 43,95 & & & 44,28 & & \\
\hline
\end{tabular}

Em relação às condições socioeconômicas, observa-se que os alunos solteiros, de cor de pele branca ou amarela, que moram sozinhos ou com os pais, cuja família apresenta renda maior que seis salários mínimos e não trabalham apresentaram melhor desempenho, com diferença estatisticamente significativa. Da mesma forma, alunos que receberam bolsas-permanência e eram cotistas, apresentaram melhor desempenho, não apresentando diferença estatisticamente significativa apenas os cotistas concluintes de universidades.

Quanto à escolarização, alunos que cursaram majoritariamente ou completamente o ensino médio em escola privada e apresentaram pais e mães com escolaridade mínima de ensino médio também obtiveram melhor desempenho, sendo a diferença estatisticamente significante.

Já os hábitos de estudo sinalizam que o melhor desempenho foi daqueles que recebiam algum tipo de bolsa acadêmica (monitoria, tutoria, iniciação à pesquisa, extensão, bolsa PET-Saúde), participaram de programas ou atividades curriculares no exterior e dedicaram oito ou mais horas por semana aos estudos, excetuando as horas de aula. Achados similares são evidenciados em outros estudos (Felicetti, Morosini e Somers, 2013).

Outra questão que o estudo sinaliza é o desempenho sempre superior das universidades em relação à análise ao se considerar todas as IESs, independentemente da organização acadêmica, com diferença estatisticamente significativa. O Gráfico 1 permite identificar, claramente, essa diferença. 
Gráfico 1

Diferença entre o desempenho dos alunos dos cursos da área da Saúde por condições socioeconômicas, escolarização da família e hábitos de estudo, em todas as instituições de ensino superior e universidades, Enade, 2013.

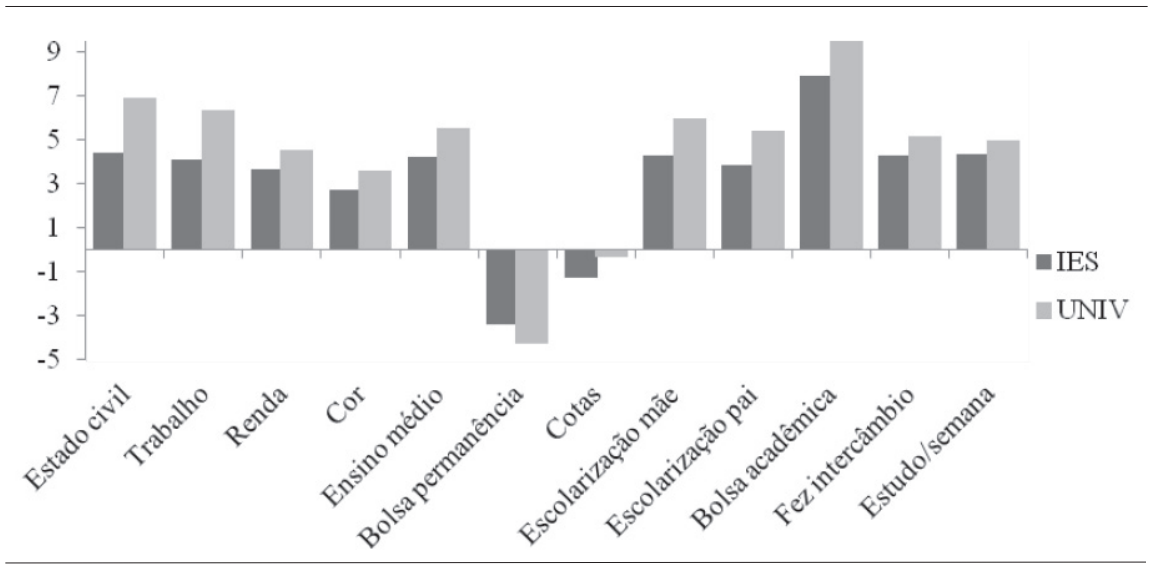

Fonte: Inep, 2016

O gráfico permite observar que o melhor desempenho refere-se aos concluintes das universidades. Outra questão bastante relevante a se observar é que as variáveis 'cotas' e 'bolsa-permanência', vinculadas à pior condição socioeconômica, apresentam comportamento diferente das outras, classicamente relacionadas às melhores condições socioeconômicas, uma vez que cotistas e bolsistas apresentaram desempenho acadêmico mais satisfatório do que os alunos fora dessa condição.

\section{O papel dos distintos fatores no desempenho acadêmico}

No presente estudo, observou-se que jovens de cor branca ou amarela, com renda acima de seis salários mínimos, solteiros e que não precisaram trabalhar ao longo da graduação tiveram melhor desempenho no Enade 2013. Enquanto o Instituto Brasileiro de Geografia e Estatística (IBGE), em 2010, concluía que $48 \%$ da população brasileira era composta por brancos e amarelos, a presente pesquisa mostra que o percentual de alunos brancos e amarelos nas IESs na área da saúde atinge 59,8\%, confirmando a hegemonia da população branca estampada nas instituições de educação brasileiras (Ristoff, 2014; Silva, Vendramini e Lopes, 2010). A questão da raça merece aprofundamento, uma vez que o preconceito, na compreensão de Lima (2013), vem estampado na própria percepção docente quando sinalizam relação entre avaliações negativas com negros e pior nível socioeconômico. O referido autor observa maior quantidade de alunos negros em atividades de reforço acadêmico, assim como relato docente sobre superioridade 'branca' no desempenho estudantil. 
A necessidade de o aluno trabalhar também tem sido considerada uma condição importante no desempenho dos cursos de graduação. Alunos que trabalham durante a formação superior passam por algumas limitações, como a reduzida disponibilidade de tempo para estudo individual, cansaço físico e responsabilidade pelas tarefas do cotidiano. Esses elementos parecem ter papel fundamental no desenvolvimento de atividades e atenção durante as aulas, o que acaba por repercutir em seu desempenho acadêmico (Campos et al., 2017). Outro elemento que fortalece essa perspectiva é que esses alunos, na grande maioria das vezes, não desenvolvem suas atividades laborais em empregos que tenham articulação com sua formação. Ou seja, o trabalho visa a sua manutenção (quando não da família), representando um esforço a mais em sua atividade cotidiana. Com isso, a restrição de tempo vivida por esses discentes no trabalho compete com as atividades acadêmicas, determinando pior desempenho ao longo de sua formação (Niquini et al., 2015). Tal estudo confirma os achados de Ristoff (2014), o qual atesta que os campi brasileiros são significativamente mais ricos que o conjunto da sociedade brasileira. Ristoff (2014) reafirma o observado por Senkevics (2018) para o qual as desigualdades sociais devem ser objeto de permanente intervenção do Estado, em função do padrão estruturante da sociedade brasileira, contribuindo para a reversão do quadro histórico de injustiças contra grandes parcelas da população brasileira.

Uma das grandes vantagens que o diferencial socioeconômico possibilita aos alunos é uma melhor condição de investir em seus estudos. Do mesmo modo, podem participar de atividades proporcionadas pelas IESs, reforçando que as condições diferenciadas que esses alunos têm para um completo envolvimento e dedicação representam significativo impacto no seu desempenho acadêmico. Vale ainda ressaltar que, apesar das intenções de se aumentar o ingresso por meio de medidas que buscam maior equidade, quem acaba conseguindo ter acesso à universidade pública, especialmente nos cursos mais concorridos, são os alunos com condições socioeconômicas diferenciadas em relação à população brasileira (Oliveira e Melo-Silva, 2010). Plasencia et al. (2008) observam que, além do pior desempenho acadêmico, as condições socioeconômicas aparecem como um dos principais fatores para uma maior chance de o aluno abandonar o seu curso de graduação.

Com essa contextualização, e conforme sinalizado por David et al. (2018), fica evidente a necessidade de se fortalecer a dimensão política da formação em saúde. Isto porque, ao se pensar na inclusão da sociedade nas decisões das mais distintas naturezas, é fundamental reconhecer o papel que as diferenças socioeconômicas representam no acesso à Educação Superior. Considerando a heterogeneidade na situação epidemiológica da população, tal identificação traz como fundamental essa compreensão para que o profissional de saúde possa, efetivamente, se envolver com os principais problemas da população, trabalhando como aliado na busca das melhores soluções. Esse reconhecimen- 
to também é fundamental quando se destaca a formação no Sistema Único de Saúde como elemento essencial no fortalecimento de um sistema de saúde universal e garantido pelos recursos públicos, que beneficiem o conjunto da sociedade brasileira, considerando suas diferenças e necessidades específicas.

Em relação à escolarização dos pais, relata-se que jovens que provêm de estratos sociais mais elevados sofrem influência dos progenitores para a escolha profissional, os quais possuem condições financeiras favoráveis para investir na formação dos filhos (Zago, 2006). Essa afirmação pode ser confirmada pelos achados deste estudo, quando foi encontrada uma forte influência da escolaridade dos pais e das mães no melhor desempenho dos alunos no Enade. Em outro estudo, Piotto e Nogueira (2016) afirmam que ter pais que atingiram certo grau de escolaridade favorece o ingresso na universidade de forma mais significativa do que a própria renda. Isto porque esses alunos obtêm, com seus pais, um capital de informações sobre as diferentes possibilidades de percurso ao longo da Educação Superior.

Para Alves (2010), o grau de escolaridade dos pais é o indicador mais utilizado para medir o capital cultural das famílias, por tratar-se da forma institucionalizada representada pelos títulos reconhecidos. Nessa mesma dimensão, a escolaridade dos pais é apontada como determinante no desempenho dos filhos no mercado de trabalho. Nesse sentido, sinaliza-se o potencial que o padrão educacional da família pode desempenhar na determinação da elevada disparidade de rendimentos quando esse referencial é considerado (Reis e Ramos, 2011).

Da mesma forma que no presente estudo, Alves (2010) encontra evidências de que filhos de pai com escolaridade média ou superior apresentam melhor desempenho escolar do que aqueles cujos pais têm escolaridade até o nível fundamental.

Por meio das atividades de pesquisa proporcionadas pelos programas de iniciação científica, os bolsistas despertam para o questionamento crítico e o desenvolvimento de habilidades instrumentais para aplicação de métodos científicos. A realização de suas investigações iniciais e divulgação destas em eventos científicos, bem como a relação estreita criada entre orientador e orientando, são formas de construir uma atitude positiva e uma autoconfiança nesses alunos, que têm o privilégio de poderem desfrutar desse contexto no decorrer da graduação (Erdmann et al., 2010).

Mesmo em cursos de medicina, nos quais a iniciação científica envolve pequena parcela de alunos, é praticamente unânime, na perspectiva dos alunos, a necessidade de envolvimento com a pesquisa, considerando seu potencial na busca do conhecimento e tomada de decisão com base científica (Oliveira, Alves e Luz, 2008).

É fundamental, entretanto, ressaltar que o papel da iniciação científica extrapola o estímulo à pesquisa, uma vez que seu desenvolvimento na gradu- 
ação deve contribuir com resultados pedagógicos para a formação intelectual, moral, crítica e criativa do estudante, permitindo, também, sua inserção nos espaços de ensino e extensão (Pinho, 2017).

A análise dos resultados permite, ainda, afirmar que a lei das cotas não influenciou no rendimento dos alunos, ou seja, percebeu-se que, independentemente da forma de acesso, o critério de seleção dos alunos é capaz de escolher os mais bem preparados e garantir a formação com qualidade dos futuros profissionais (Queiroz et al, 2015).

Contrariando resultados de Lopes (2017), o presente estudo observou a perspectiva da inclusão de cotistas em cursos que representam campos de estudo de grande relevância como são os cursos da área da saúde. Constatouse que o desempenho dos cotistas no Enade 2013 foi superior ao dos alunos que não eram cotistas, o que sinaliza a perspectiva da política de cotas como potencial estratégia para a diminuição da desigualdade entre os grupos raciais e sociais envolvidos.

Alunos cotistas tiveram desempenho equivalente ao de seus colegas de classe não cotistas, assim como aqueles que recebem empréstimo do FIES (Wainer e Melguizo, 2017). As análises indicam desempenho superior de não cotistas, sendo observada considerável magnitude da diferença $[6,81 \%$ $(\mathrm{F}=348,114, \mathrm{p}<.000)]$ quando os dois grupos são diretamente comparados. Quando separados por área de conhecimento, os cotistas apresentam desempenho superior em cursos das áreas de artes e humanidades, considerados de média e baixa concorrências (Peixoto et al., 2016).

Os resultados do presente estudo confirmam achados de Araújo e Leite (2014) os quais concluíram que a bolsa-permanência é um elemento fundamental para continuidade do estudante no curso de graduação. Da mesma forma, Hernandez, Larenas e Salgado (2017) observaram em Concepción (Chile), que as bolsas-permanência representam um ponto de inflexão no curso das políticas públicas, sinalizando para a necessidade de se prover mais apoio às atividades acadêmicas.

Na verdade, o diferencial do presente estudo foi constatar a importância da bolsa-permanência, uma vez que alunos com esse recurso apresentaram desempenho superior, inclusive, em relação aos alunos com melhores condições socioeconômicas.

Vale ressaltar, ainda em relação à bolsa-permanência, que os ordenamentos legais das universidades que oferecem ações afirmativas dessa natureza comportam fórmulas variadas e complexas que podem impossibilitar o entendimento daqueles que mais poderiam se beneficiar dessas ações.

Os cálculos dificultam a comunicação e o entendimento da mensagem que as universidades querem veicular, uma vez que requerem interpretação especializada (Sousa e Portes, 2011). 
Os resultados do presente estudo sinalizam que as bolsas-permanência, aparentemente, são um mecanismo para diminuir a inadequação proporcionada pela falta de maior articulação entre as políticas de equidade da Educação Superior, as quais levam os alunos a arcarem com custos muitos maiores do que permitem suas condições financeiras, conforme afirmado por Rossetto e Gonçalves (2015).

Outro elemento que também mereceu destaque relativo a um diferencial no desempenho dos alunos foi a participação em intercâmbio. Segundo Guedes, Cavalcante e Puschel (2018), essa estratégia possibilita uma formação diferenciada ao favorecer o desenvolvimento pessoal e profissional, tanto na perspectiva de estimular o aluno na tomada de decisão como na vivência de situações diferenciadas de seu cotidiano. O intercâmbio também desperta o desenvolvimento técnico-científico, cultural e as ideias inovadoras, contribuindo, inclusive, para sua futura inserção no campo de trabalho.

Uma das principais limitações do estudo referiu-se à impossibilidade de consulta aos dados primários ao longo da análise dos resultados, uma vez que o acesso a eles somente era possível no ambiente seguro do Inep. Essa limitação exigiu que todo o planejamento relativo ao plano de análise estatística fosse preliminarmente definido, o que impossibilitou novas análises com base nas inferências identificadas ao longo do estudo. Outra limitação referese à utilização de dados de desempenho dos alunos concluintes a partir do Enade, considerando que o exame trata de um conjunto de itens elaborados para finalidade de avaliação institucional oriunda da articulação com outros elementos, como avaliação in loco e censo da Educação Superior. Entretanto, numa perspectiva global, o Enade corresponde à parte das habilidades e conhecimentos requeridos dos estudantes no âmbito das Diretrizes Curriculares Nacionais dos diferentes cursos da área da saúde (Wainer e Melguizo, 2018).

\section{Considerações finais}

A nítida barreira que estudantes e famílias de classes sociais mais desfavorecidas apresentam para ingresso na educação superior no Brasil requer uma permanente busca de maior justiça social, baseada em melhor distribuição de renda e estratégias que sinalizem para a equidade. Políticas baseadas na redução do investimento público em saúde, educação, moradia e segurança - entre outras prioridades - representam um acréscimo de tempo na perpetuação de direitos menos equanimemente distribuídos, considerando os movimentos pouco efetivos para a melhor distribuição de renda. Assim, enquanto se mantiver a atual situação econômica do país, de forte concentração de renda e marcantes injustiças sociais, é papel do governo dar suporte às pessoas com piores condições socioeconômicas. Além disso, o Estado deve adotar estratégias que viabilizem o acesso à Educação Superior por meio 
de políticas afirmativas, bem como utilizar recursos públicos para viabilizar que essas pessoas tenham condições adequadas de investir em sua formação.

Nesse sentido, a concessão de bolsas-permanência representou, no presente estudo, um diferencial na perspectiva de permitir que alunos em condição de maior vulnerabilidade, além de concluírem seu curso, apresentassem melhor desempenho no Enade 2013, quando comparado com aqueles com condições socioeconômicas mais adequadas. Vale ressaltar que o custo dessas bolsas-permanência é suficiente para que o aluno, minimamente, mantenha suas necessidades básicas relativas à alimentação e a deslocamento. Aparentemente, o que faz a diferença representada por esse incentivo é o empenho do aluno, privado ao longo da vida às condições mínimas de acesso aos ensinos fundamental e médio de qualidade, na busca de caminhos mais prósperos em seu futuro, graças à formação em um curso superior na área da Saúde.

Da mesma forma, o investimento em bolsas acadêmicas é uma das principais estratégias e deve ser priorizada, pois permite maior envolvimento do aluno com a IES. Desse modo, o bolsista consolida seu aprendizado, pois aprofunda o vínculo com a iniciação à docência e aos estudos científicos, bem como aos projetos de extensão. Deve ser orientado às IESs que identifiquem estratégias que permitam aos alunos em piores situações socioeconômicas acesso mais facilitado às bolsas acadêmicas, promovendo dessa forma uma sensível contribuição para a equidade.

\section{CONDICIONES SOCIALES, ESCOLARIZACIÓN Y HÁBITOS DE ESTUDIO EN EL DESEM- PEÑO ACADÉMICO DE GRADUADOS DEL ÁREA DE LA SALUD}

\footnotetext{
Resumen Varios factores contribuyen a la dificultad en el acceso y permanencia en la Educación Superior en Brasil. El objetivo de este estudio fue identificar la diferencia de desempeño de los estudiantes por condiciones socioeconómicas, escolarización y hábitos de estudio. Fue realizado un estudio transversal analítico con base en los datos del Examen Nacional de Desempeño de los Estudiantes, en alrededor de 196.856 alumnos de los cursos de salud en 2013. La nítida barrera que estudiantes de clases sociales menos favorecidas presentan para ingreso y permanencia en la Educación Superior requiere una permanente búsqueda de mayor justicia social. Mientras se mantenga la actual situación, es papel del gobierno proporcionar estrategias que viabilicen el acceso a Educación Superior por medio de políticas afirmativas y recursos para viabilizar que personas con peores condiciones socioeconómicas puedan invertir en su formación. La beca-permanencia se presentó como esencial en la búsqueda de equidad, así como la beca académica permitió mejor desempeño, en especial, por mayor vínculo con la Institución de Educación Superior.
}

Palabras clave educación superior; condiciones socioeconómicas; escolarización; hábitos de estudio; equidad. 


\section{Colaboradores}

Luiz Roberto Augusto Noro participou da concepção e redação do projeto de pesquisa, da revisão crítica da literatura, do planejamento do estudo, da coleta e interpretação dos dados e da revisão crítica do manuscrito. José Luis Medina Moya participou da concepção do projeto, da revisão crítica da literatura, do planejamento do estudo e da revisão crítica do manuscrito. Não há conflito de interesses.

\section{Financiamento}

O presente trabalho foi realizado com apoio da Coordenação de Aperfeiçoamento de Pessoal de Nível Superior (CAPES) - Código de Financiamento 001. 


\section{Referências}

ALVES, Maria T. G. Dimensões do efeito das escolas: explorando as interações entre famílias e estabelecimentos de ensino. Estudos em Avaliação Educacional, São Paulo, v. 21, n. 46 , p. 271-296, 2010

ALVES, Maria T. G.; SOARES, José. F.; XAVIER, Flávia. P. Índice socioeconômico das escolas de educação básica brasileiras. Ensaio: Avaliação e Políticas Públicas em Educação, Rio de Janeiro, v. 22, n. 84, p.671-703, 2014.

ARAÚJO, Jair C. F; LEITE, Lígia S. Avaliação da política de apoio ao estudante desenvolvida pela UNIRIO: o projeto de Bolsa Permanência. Avaliação e Politicas Públicas em Educação, Rio de Janeiro, v. 22, n. 84, p.777-806, 2014.

BROCCO, Ana K. “Aqui em casa a educação é muito bem-vinda": significado do ensino superior para universitários bolsistas. Revista Brasileira de Estudos Pedagógicos, v. 98, n. 248, p. 94-109, 2017.

CAMPOS Larissa C. et al. Social quotas, affirmative actions and dropout in the business field: empirical analysis in a Brazilian federal university. Revista Contabilidade e Finanças, São Paulo, v. 28, n. 73, p. 27-42, 2017.

DAVID, Helena M. S. L. et al. Curso para a formação histórico-política na graduação em saúde: análise de uma construção partilhada. Trabalho, Educação e Saúde, Rio de Janeiro, v. 16, n. 3, p. 997-1015, 2018.

ERDMANN, Alacoque. L. et al. Vislumbrando o significado da iniciação científica a partir do graduando de enfermagem. Escola Anna Nery Revista de Enfermagem, Rio de Janeiro, v. 14, n. 1, p. 26-32, 2010.

FELICETTI, Vera L.; MOROSINI, Marília C. Equidade e iniquidade no ensino superior: uma reflexão. Ensaio: Avaliação e Políticas Públicas em Educação, Rio de Janeiro, v. 17, n. 62, p. 9-24, 2009.
FELICETTI, Vera L.; MOROSINI, Marília C.; SOMERS, Patricia. Affirmative action in the quality of Higher Education: the voices of graduates of the University for All program. Policy Futures in Education, v.11, n. 4, p. 40113, 2013.

FERNÁNDEZ, José T. La evaluación de las competencias en contextos no formales: dispositivos e instrumentos de evaluación. Revista de Educación, Madrid, n. 354, p. 731-745, 2011.

FONSECA, Zilma. Exclusão-inclusão: circularidade perversa no Brasil contemporâneo. Revista Trabalho, Educação e Saúde, Rio de Janeiro, v. 12, n. 2, p. 231-252, 2014.

FORMIGA, Nilton S. O tipo de orientação cultural e sua influência sobre os indicadores do rendimento escolar. Psicologia: Teoria e Prática, São Paulo, v. 6, n. 1, p. 13-29, 2004.

GUEDES, Glauteice F; CAVALCANTE, Inara M. S.; PUSCHEL, Vilanice A. A. Mobilidade estudantil internacional: a experiência de estudantes de graduação em Enfermagem. Revista da Escola de Enfermagem da USP, São Paulo, v. $52, \mathrm{e} 03358,2018$

HAAS, Cecília M.; LINHARES, Milton. Políticas públicas de ações afirmativas para ingresso na educação superior se justificam no Brasil? Revista Brasileira de Estudos Pedagógicos, Brasília, v. 93, n. 235, p.836-863, 2012.HERNANDEZ, Valentina S.; LARENAS, Claudio D.; SALGADO, María T. C. Beca de nivelación académica: resultados de un programa de intervención en estudiantes de origen vulnerable en la Universidad de Concepción. Educação em Revista, Belo Horizonte, v. 33, el60071, 2017.

LIMA, Leonardo C. A. Uma trama intrincada: as complexas interações entre gênero e raça na avaliação da aprendizagem discente. Revista Brasileira de Estudos Pedagógicos, Brasília, v. 94, n. 236, p. 323-326, 2013.

LIMA, Paulo G. Universalização da educação superior no Brasil: contrapontos e possibili- 
dades. Educação em Revista, Belo Horizonte, n. 51, p.243-264, 2014.

LOPES, Alice D. Affirmative action in Brazil: how students' field of study choice reproduces social inequalities. Studies in Higher Education, Oxford, v. 42, n. 12, p. 2343-2359, 2017.

MAIO, Marcos C.; SANTOS, Ricardo V. Cotas e racismo. In: FRY, Peter H. et al. (Org.). Divisões perigosas: políticas raciais no Brasil contemporâneo. Rio de Janeiro: Civilização Brasileira, 2007. p. 161-165.

NIQUINI, Roberta P. et al. Características do trabalho de estudantes universitários associadas ao seu desempenho acadêmico. Educação em Revista, Belo Horizonte, v. 31, n. 1, p. 359-381, 2015.

NORO, Luiz R. A. et al. Relação entre conteúdos das disciplinas de curso de odontologia e os ENADE 2004/2010. Avaliação, Campinas, v. 22, n. 1, p. 125-39, 2017.

OLIVEIRA, Melina D. A.; MELO-SILVA, Lucy L. Estudantes universitários: a influência das variáveis socioeconômicas. Psicologia Escolar e Educacional, São Paulo, v. 14, n. 1, p. 23-34, 2010.

OLIVEIRA, Neilton A.; ALVES, Luiz A.; LUZ, Madel. R. Iniciação científica na graduação: o que diz o estudante de medicina? Revista Brasileira de Educação Médica, Brasília, v. 32, n. 3, p.309-314, 2008.

PEIXOTO, Adriano L. A. et al. Cotas e desempenho acadêmico na UFBA: um estudo a partir dos coeficientes de rendimento. Avaliação, Campinas, v. 21, n. 2, p. 569-592, 2016.

PINHO, Maria J. Ciência e ensino: contribuições da iniciação científica na educação superior. Avaliação, Campinas, v. 22, n. 3, p. 658-675, 2017.

PIOTTO, Débora C.; NOGUEIRA, Maria A. Incluindo quem? Um exame de indicadores socioeconômicos do Programa de Inclusão Social da USP. Educação e Pesquisa, São Paulo, v. 42, n. 3, p. 625-649, 2016.

PLASENCIA, Carrera S. R. et al. Estudio: factores socio-económicos y su relación con el rendimiento académico en estudiantes de la Universidad Nacional de Cajamarca. 2008. Disponível em: <http://nuevo.unc.edu.pe/ paginas/educacion/IIEDUCA/Archivos/Articulo $\%$ 20Cientifico $\% 20$ - $\%$ 20PLASENCIA $\% 20$ CARRERA.pdf > . Acesso em: 15 jul. 2018.

QUEIROZ, Zandra C. L. S. et al. A lei de cotas na perspectiva do desempenho acadêmico na Universidade Federal de Uberlândia. Revista Brasileira de Estudos Pedagógicos, Brasília, v. 96, n. 243, p.299-320, 2015.

REIS, Maurício C.; RAMOS, Lauro. Escolaridade dos pais, desempenho no mercado de trabalho e desigualdade de rendimentos. Revista Brasileira de Economia, Rio de Janeiro, v. 65, n. 2, p.177-205, 2011.

RISTOFF, Dilvo. O novo perfil do campus brasileiro: uma análise do perfil socioeconômico do estudante de graduação. Avaliação, Campinas, v. 19, n. 3, p. 723-747, 2014.

RODRIGUES, Clarissa G. et al. Diferenças intertemporais na média e distribuição do desempenho escolar no Brasil: o papel do nível socioeconômico, 1997 a 2005. Revista Brasileira de Estudos de População, Rio de Janeiro, v. 28, n. 1, p.5-36, 2011.

ROSSETTO, Cristina B. S.; GONCALVES, Flávio. O. Equidade na educação superior no Brasil: uma análise multinomial das políticas públicas de acesso. Dados, Rio de Janeiro, v. 58, n. 3, p.791-824, 2015.

SANTOS, Elizabete F.; SCOPINHO, Rosemeire A. Desigualdades raciais, mérito e excelência acadêmica: representações sociais em disputa. Psicologia: Ciência e Profissão, Brasília, v. 36, n. 2, p.267-279, 2016.

SENKEVICS, Adriano S. Contra o silêncio racial nos dados universitários: desafios e propostas 
acerca da Lei de Cotas. Educação e Pesquisa, São Paulo, v.44, e182839, 2018.

SILVA, Marjorie C. R.; VENDRAMINI, Claudette M. M.; LOPES, Fernanda L. Diferenças entre gênero e perfil socioeconômico no exame nacional de desempenho do estudante. Avaliação, Campinas, v. 15, n. 3, p.185-202, 2010.

SOUSA, Letícia P.; PORTES, Écio. A. As propostas de políticas/ações afirmativas das universidades públicas e as políticas/ações de permanência nos ordenamentos legais. Revista Brasileira de Estudos Pedagógicos, Brasília, v. 92, n. 232, p. 516-541, 2011.
SOUZA, Davisson C. C.; VAZQUEZ, Daniel A. Expectativas de jovens do ensino médio público em relação ao estudo e ao trabalho. Educação e Pesquisa, São Paulo, v. 41, n. 2, p.409-426, 2015.

WAINER, Jacques; MELGUIZO, Tatiana. Políticas de inclusão no ensino superior: avaliação do desempenho dos alunos baseado no ENADE de 2012 a 2014. Educação e Pesquisa, São Paulo, v. 44, e162807, 2018.

ZAGO, Nadir. Do acesso à permanência no ensino superior: percursos de estudantes universitários de camadas populares. Revista Brasileira de Educação, Rio de Janeiro, v. 11, n. 32, p. 226-237, 2006. 